\title{
Effect of electrode material on removal efficiency regarding single discharges in wire EDM
}

\author{
Lukas Welschof $^{1}$ • Niklas Schäfer ${ }^{1} \cdot$ Tim Herrig $^{1} \cdot$ Andreas Klink $^{1} \cdot$ Thomas Bergs $^{1}$
}

Received: 7 January 2021 / Accepted: 8 August 2021 / Published online: 16 September 2021

(C) The Author(s) 2021

\begin{abstract}
For the precise machining of demanding materials, wire electrical discharge machining (WEDM) is a flexible and often irreplaceable manufacturing process. In order to enhance productivity as the main focus of the wire EDM process, the advancement of the fundamental procedural understanding is of decisive importance. In order to be able to energetically evaluate the removal process, the individual energetic contributors of the process hence the individual discharges need to be understood in terms of their contribution to material removal. In this paper, an experimental setup is presented, which permits the generation of individual discharges on a modern industrial wire EDM machine tool. For three different wire electrodes, the correlation of the discharge energy and the individual removal volume is quantitatively described, showing that coated wires achieve a significantly higher energy-specific removal. Furthermore the removal efficiency is defined as a key figure to transfer the findings to the continuous process and compare theoretical and effective removal rate.
\end{abstract}

Keywords Wire EDM $\cdot$ Single discharges $\cdot$ Electrode material $\cdot$ Removal efficiency

\section{Nomenclature}

a Orthogonal crater dimension / $\mu \mathrm{m}$

A- $\quad$ Crater area $/ \mu \mathrm{m}^{2}$

A+ $\quad$ Rim area $/ \mu \mathrm{m}^{2}$

b Vertical crater dimension $/ \mu \mathrm{m}$

h- $\quad$ Crater depth $/ \mu \mathrm{m}$

$\mathrm{h}+\quad$ Rim height $/ \mu \mathrm{m}$

ie Discharge current / A

$\mathrm{rN} \quad$ Percentage of normal discharges / \%

rRC Relative rim volume $\left(\mathrm{V}+/ \mathrm{V}^{-}\right) / \%$

sm Average clearance (kerf width) $/ \mu \mathrm{m}$

t0 Pulse interval time / $\mu$ s

te $\quad$ Discharge duration $/ \mu \mathrm{s}$

$\mathrm{V}-\quad$ Crater volume $/ \mu \mathrm{m}^{3}$

$\mathrm{V}+\quad$ Rim volume $/ \mu \mathrm{m}^{3}$

$\mathrm{vE} \quad$ Energy-specific material removal (VWe/We) / $\left(\mu \mathrm{m}^{3} / \mathrm{mJ}\right)$

Lukas Welschof

1.welschof@wzl.rwth-aachen.de

1 Laboratory for Machine Tools and Production Engineering WZL, RWTH Aachen University, Campus-Boulevard 30,

52074 Aachen, Germany

$\begin{array}{ll}\text { VW } & \text { Cutting rate } /\left(\mathrm{mm}^{2} / \mathrm{min}\right) \\ \text { VW,eff } & \text { Experimental removal rate } /\left(\mathrm{mm}^{3} / \mathrm{min}\right) \\ \text { VW,theo } & \text { Theoretical removal rate } /\left(\mathrm{mm}^{3} / \mathrm{min}\right) \\ \text { VWe } & \text { Material removal per discharge } / \mathrm{\mu m}^{3} \\ \mathrm{We} & \text { Discharge energy } / \mathrm{mJ} \\ \eta & \text { Removal efficiency (single disch. }) / \% \\ \eta \mathrm{R} & \text { Removal efficiency (cont. process }) / \%\end{array}$

\section{Introduction}

The advancement of the fundamental procedural understanding is of decisive importance for electrical discharge machining in order to push the boundaries of productivity. This typically is addressed by investigating continuous erosion processes on the one hand and analyzing single discharges on the other hand. In contrast to die-sinking EDM, there are very few studies of individual discharges that have been produced on representative state-of-the-art industrial wire EDM machines. This is mostly due to the fact that complex machine kinematics hamper the implementation of a robust experimental setup. Although the plasma-physical phenomena of the two process variants are essentially comparable, it has to be assumed that the determining removal characteristics for typical wire and 
sinking EDM technologies are quite different due to differences in electrode polarity, current forming, maximum current, current gradients, discharge duration, and different electrode materials [1].

In 2001, Nöthe investigated single discharges in micro wire EDM, which he achieved by means of a short, lateral deflection movement of the wire. As a result, several locally separated discharges were evaluated. This procedure did not allow a clear assignment to the corresponding current and voltage signals [2].

In 2007, Han et al. analyzed the influence of the discharge duration on the crater form for wire EDM finishing with low energies, without describing the experimental setup. They found discharges of the same energy level to result in similar surface roughness values when varying discharge duration. Lower discharge energies showed distinctively smaller craters for longer discharge durations [3].

In 2012, Kamenzky investigated single discharges with additivated and non-additivated dielectrics on a modified micro sinking EDM machine by means of integrating wire kinematics to the setup. She found an inversely proportional relationship between gap width and crater diameter for discharge energies in the milliamp range. An enlarged working gap results in a greater loss of discharge energy available for melting and vaporizing to the dielectric by dissipation [4].

In 2014, Zhang et al. conducted investigations of the material removal behavior of single discharges with different dielectrics for sinking EDM. The authors described the effects of the energy variation by changing pulse duration on the crater shape using geometric crater properties. Two different crater types were identified in terms of crater morphology, which differ in terms of the removed material volume. The ratio of molten material volume to removed volume determines the removal efficiency $\eta$ of a single discharge [5].

In 2017, Schwade carried out analogy tests on single discharges on a sinking EDM machine, which he parameterized in a way similar to wire EDM. Using magnesium and steel, he compared the material influence on crater size and topography. The discharge current investigated was only about onefiftieth of the discharge currents modern wire EDM machines apply. At the same time, the discharge durations were greater by a factor of 3-25 [6].

In 2018, Klocke et al. investigated the influence of polarity on single discharges, consecutive discharges, and in the continuous sink erosion process. For both Ti6Al4V and the steel $42 \mathrm{CrMo} 4$, higher crater volumes were obtained under cathodic tool polarity with a simultaneously smaller crater diameter. The rim zone exhibited a smaller thickness under cathodic tool polarity. During consecutive discharges and in the continuous process, a higher removal rate was obtained with anodic tool polarity [7].

In 2020, Li and Yang studied the movements of the plasma channel on the electrode in the course of a single discharge and recorded them with a high-speed camera. They found more movement with cathodic workpiece polarity, which resulted in a more irregular crater morphology compared to anodic workpiece polarity. Faster and further movement of the plasma footpoint was also achieved by increased discharge currents and smaller working gaps. In addition, the mobility was limited with a pointed compared to a flat electrode bottom [8].

Especially in wire EDM, in addition to the progress made in generator technology, the development of optimized tool electrodes has also contributed significantly to increase the process productivity. Most important wire characteristics for productive and stable machining are high electrical conductivity, high melting point, and high tensile strength of the electrode material [9]. In the literature, the enhancement of sparking properties by coating of zinc and its alloys is described as superior to negative effect through decrease in electrical conductivity [10]. The coating's lower melting temperature results in evaporation and thus a cooling effect of the core wire leading to a more intense thermal flow, better flushability through enlarged gap size, and an increased cutting speed [11]. The quick wear of the thin zinc coating during machining is addressed with the design of diffusion annealed coated wires. These coatings are more resistant to wear while maintaining the good sparking properties of zinc coating [9].

This paper aims to explain differences in macroscopic productivity by analyzing single discharges in wire EDM. For this purpose, the influence of the discharge energy on the material removal of a single discharge is quantified for different wire electrodes. The influence of the wire electrode on the individual material removal then allows an evaluation of the removal efficiency in the continuous wire EDM process.

\section{Experimental setup}

\subsection{Generation and evaluation of single discharges}

The tests were carried out on a Georg Fischer Machining Solutions (GFMS) CUT P550 wire EDM machine with water as dielectric, representing the latest industrial state of the art and allowing cutting rates of up to $\mathrm{V}_{\mathrm{W}}=400 \mathrm{~mm}^{2} / \mathrm{min}$. Since the utilized generator does not allow parameterization of individual pulses via the machine setting, an experimental setup is required to manipulate the electrical discharge circuit in such a way that the continuous erosion is interrupted with a temporal accuracy of a few microseconds directly after detection of a single discharge. The experimental setup for generating single discharges is shown in Fig. 1 and is based on an event-triggered IGBT-switch, which allows for a short circuit between electrode and workpiece in parallel to the discharge gap. The closed parallel circuit makes voltage build-up impossible and 


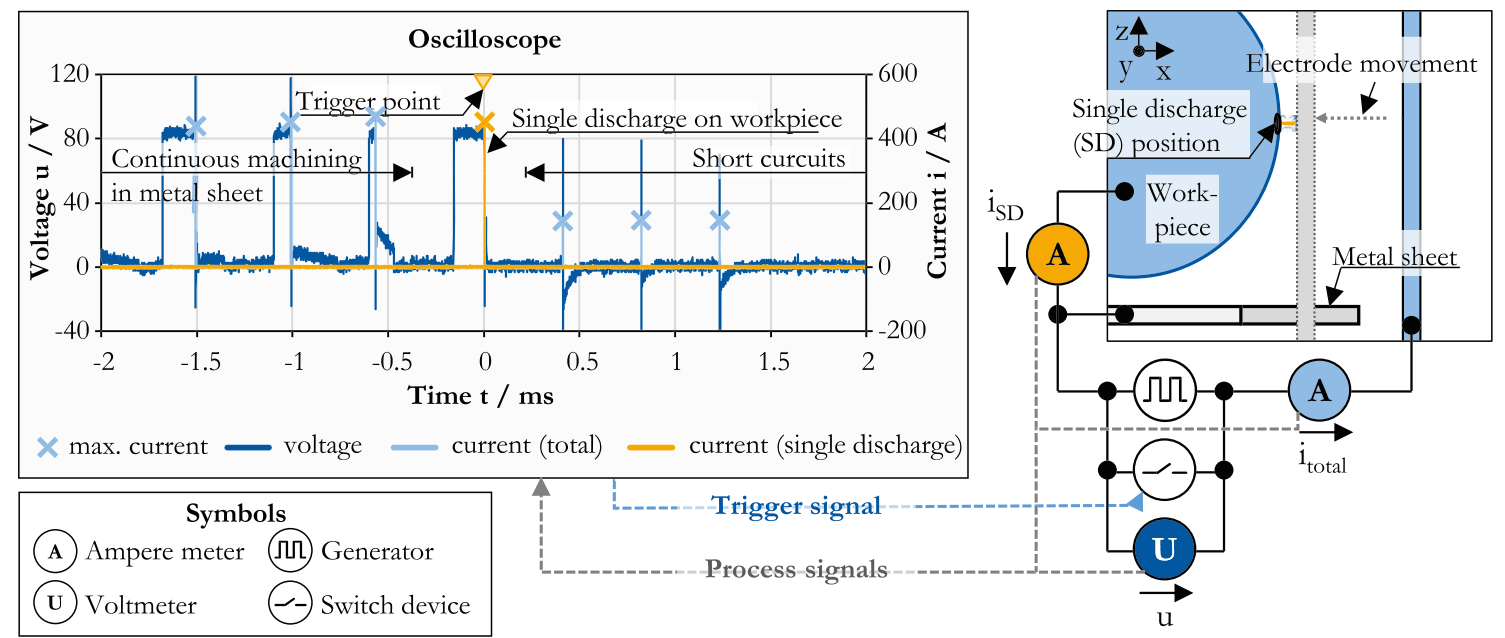

Fig. 1 Experimental setup

thus prevents reionization of the gap and stops the continuous erosion.

The rising current slope of the single discharge to be investigated functions as trigger signal. It is detected by a Tektronix DPO7104C digital storage oscilloscope and relayed via its transistor transistor logic (TTL) output signal to the IGBTswitch which closes the short circuit before the subsequent discharge. In order to perform each individually generated discharge under the same conditions, the generator is initially set into a steady state by operating in a continuous erosion process cutting a metal plate, cf. Fig. 1. In this state, the wire approaches the polished cylindrical workpiece until a single discharge occurs on the workpiece radius. Even using constant machining parameters, the resulting discharge energy shows statistical variance.

For the test series, the machine parameter I is varied as shown in Table 1 in order to set the discharge energy. Pulse interval time $t_{0}$ is maximized and kept constant. With an increase of the machine parameter "I," the maximum discharge current $\hat{l}_{\mathrm{e}}$ (investigated range: $\hat{l}_{\mathrm{e}}=100 \ldots 550 \mathrm{~A}$ ) and the discharge duration $\mathrm{t}_{\mathrm{e}}$ (range: $\mathrm{t}_{\mathrm{e}}=1,3 \ldots 2,8 \mu \mathrm{s}$ ) increase dependently. The tests are run using three differently coated wire electrodes. Other parameters such as flushing pressure or tool polarity remain constant.

Table 1 Test series specific experimental machine parameters

\begin{tabular}{ll}
\hline Wire electrodes & Brass, zinc-coated, $\gamma$-brass \\
\hline Machine parameter "I" (det. $\left.\widehat{i}_{\mathrm{e}}, \mathbf{t}_{\mathbf{e}}\right)$ & $\begin{array}{l}11,13,14,15,17,19,21 \\
\widehat{(i}_{\mathrm{e}}=100 \ldots 550 \mathrm{~A} \\
\left.\mathrm{t}_{\mathrm{e}}=1,3 \ldots 2,8 \mu \mathrm{s}\right)\end{array}$ \\
\hline
\end{tabular}

Discharge energy is calculated based on current and voltage signal recorded with the oscilloscope. The generated discharge craters are captured and volumetrically measured with a Keyence confocal laser-scanning microscope, as shown in Fig. 2. In addition to the external dimensions of the crater, its volume and the volume of the crater rim are determined.

The material removal of a single discharge $\mathrm{V}_{\mathrm{We}}$ is obtained as the difference between the crater volume $\mathrm{V}$ - and the rim volume $\mathrm{V}+$, cf. formula (1). The two volumes are determined as the concave and convex parts of the analyzed volume, respectively, originating from the polished reference surface of the component.

$\boldsymbol{V}_{W_{e}}=(\boldsymbol{V}-)-\boldsymbol{V}+$

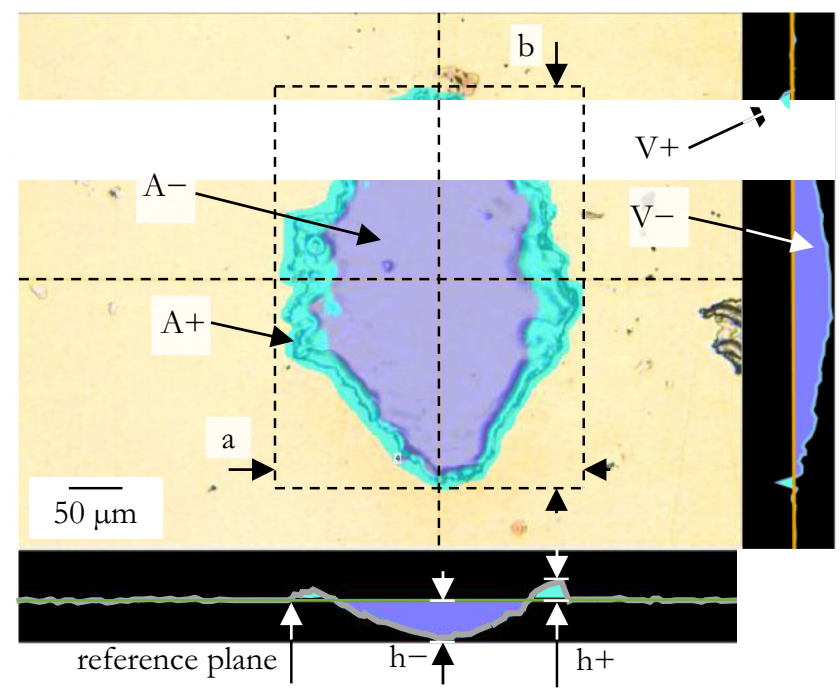

Fig. 2 Analyzed geometric features of a single discharge crater 
Concludingly, tests in the continuous process state are performed to examine the transferability of the results of the single discharge tests to the continuous process. A workpiece of Inconel 718 with a constant height of $\mathrm{h}=20 \mathrm{~mm}$ is machined in main cut with a parameter set as described in Table 2. Discharge frequency is varied via parameter P. Other parameters, such as tool polarity, are set analogously to the parameters in the single discharge tests.

During steady-state, machining cutting rate $\mathrm{V}_{\mathrm{W}}$ and average clearance $\mathrm{s}_{\mathrm{m}}$ are obtained to calculate material removal rate. Current and voltage signals are used to determine discharge frequency $\mathrm{f}_{\mathrm{e}}$, average discharge energy $\mathrm{W}_{\mathrm{e} \text {,mean }}$, and percentage of normal discharges $r_{N}$.

\subsection{Material and wire electrodes}

The workpiece material used is Inconel 718, a standard nickelbased alloy widely used in the aerospace sector for the manufacture of engine components, with thermal conductivity at $20^{\circ} \mathrm{C}$ of $\lambda_{\mathrm{W}}=11.2 \mathrm{~W} /(\mathrm{m} \cdot \mathrm{K})$ and a density of $\rho=8.19 \mathrm{~kg} / \mathrm{cm}^{2}$. Mechanical properties are comparable to other nickel-based alloys.

Three different wire electrodes with a wire diameter of $d=$ $250 \mu \mathrm{m}$ are used in the tests. These are the Bedra BercoCut Pro brass wire, the CobraCut A zinc-coated brass wire, and the Topas Plus $\mathrm{H}$ diffusion annealed $\gamma$-brass wire for high-speed cutting, cf. Fig. 3. The resulting discharge waveforms are independent of the wire electrode used.

\section{Results and discussion}

\subsection{Crater and energy-specific material removal}

With the exception of discharge energies below $\mathrm{W}_{\mathrm{e}}=5 \mathrm{~mJ}$, the discharge craters are characterized by an elliptical shape of the melt pool and the neighboring crater rim, cf. Fig. 4. The orientation of the larger ellipse axis is parallel to the wire electrode, which suggests a preferred direction of plasma channel propagation along the wire. Different workpiece diameters have no effect on the crater shape. In its center, the crater reaches its maximum depth.

With increasing discharge energy, the crater diameters and removed volumes increase. Using the brass wire, Fig. 4 shows the correlation between discharge energy and material removal per discharge. The material removal increases

Table 2 Machine parameters for the continuous process

\begin{tabular}{lllll}
\hline I & ISH & P & SPL & Ssoll \\
\hline 19 & -3 & $40,45,50$ & 7 & 30 \\
\hline
\end{tabular}

approximately proportional to the discharge energy, ranging from $\mathrm{V}_{\mathrm{We}} \approx 8,000 \mu \mathrm{m}^{3}\left(\mathrm{~W}_{\mathrm{e}}<5 \mathrm{~mJ}\right)$ to $\mathrm{V}_{\mathrm{We}} \approx 215,000 \mu \mathrm{m}^{3}$ $\left(\mathrm{W}_{\mathrm{e}}>50 \mathrm{~mJ}\right)$.

The maximum energy-specific material removal is found for the lowest discharge energies decreasing towards higher discharge energies. Fig. 4 shows that with discharge energies of $\mathrm{W}_{\mathrm{e}}>20 \mathrm{~mJ}$, the energy-specific material removal is below $\mathrm{v}_{\mathrm{E}}=5,000 \mu \mathrm{m}^{3} / \mathrm{mJ}$, while discharge energies between $\mathrm{W}_{\mathrm{e}}=5$ $-10 \mathrm{~mJ}$ exceed the energy-specific material removal of $\mathrm{v}_{\mathrm{E}}=$ $5,000 \mathrm{\mu m}^{3} / \mathrm{mJ}$. This decrease of removal volume over discharge energy confirms previous investigations by SCHWADE in sinking EDM, where a similar correlation was found [6].

The variance in material removal per discharge increases with discharge energy, which is reflected exemplarily in the range of discharge energies of $\mathrm{W}_{\mathrm{e}}=30-40 \mathrm{~mJ}$. The material removal differs between $V_{\mathrm{We}}=80,000-150,000 \mu \mathrm{m}^{3}$, which corresponds to a relative variance of over $50 \%$. The main cause of this large variance in the material removal is the disproportionately increased variance of the rim volume compared to the crater volume.

\subsection{Influence of the wire electrode material}

Applying the same test size while varying the type of wire electrode, a clear correlation between the electrode material and the crater volume was found. The energy-specific material removal is shown in Fig. 5 for single discharges with discharge energies of $15 \mathrm{~mJ} \leq \mathrm{W}_{\mathrm{e}} \leq 50 \mathrm{~mJ}$ for the three wires used. The mean energy-specific material removal $\mathrm{v}_{\mathrm{We} \text {,mean }}$ is $24.6 \%$ higher for the zinc-coated wire CobraCut A than for the bare brass wire BercoCut Pro. With the high-speed cutting wire Topas Plus H, an average of $62.7 \%$ more individual material removal volume per discharge energy is achieved than with the brass wire, cf. Fig. 5. The lowest variance in material removal is observed while using the zinc-coated wire CobraCut A. It can be stated that for the same electrical energy applied, coated wires remove significantly more workpiece material with an individual discharge under the same conditions.

The direct comparison between the brass wire BercoCut Pro and the $\gamma$-brass wire Topas Plus $\mathrm{H}$ with regard to the relative rim volume $r_{R C}$ (cf. Formula 2) is shown in Fig. 6 to illustrate the geometric characteristics of the discharge crater

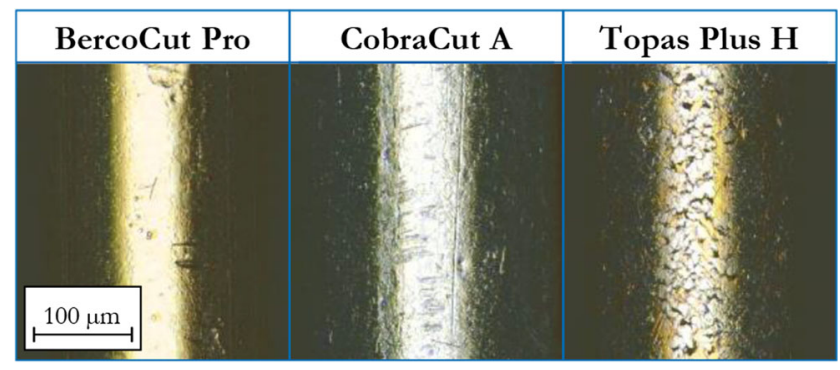

Fig. 3 Microscopic images of the wire electrodes used 


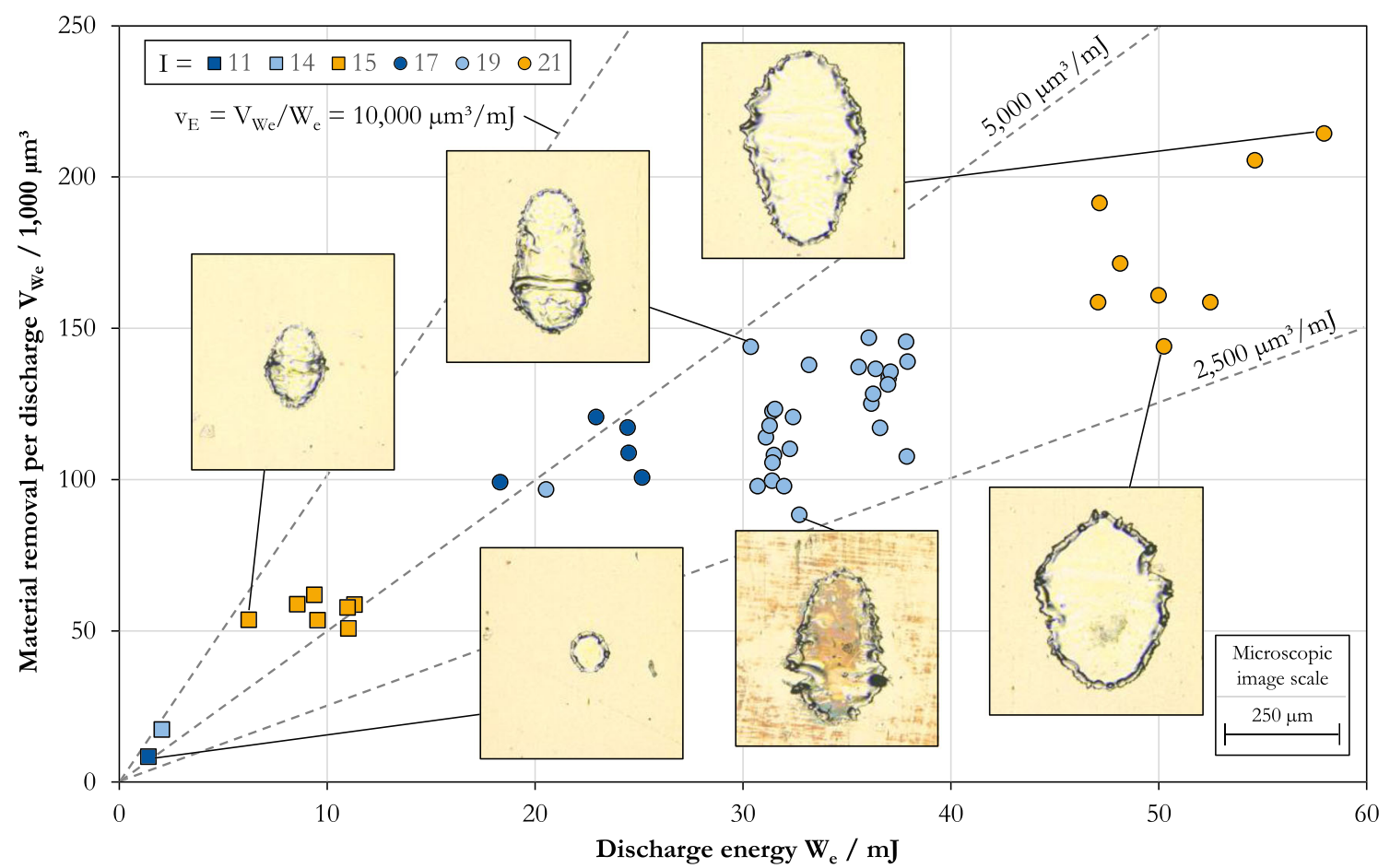

Fig. 4 Correlation between material removal per discharge and discharge energy (using BercoCut Pro)

that are causal for the wire-specific material removals.

$r_{R C}=\frac{V+}{V-}$

On the one hand, a relative rim volume $\mathrm{r}_{\mathrm{RC}}$ increasing with the discharge energy is observed for both wires. This observation corresponds to the decrease of the energy-specific material removal with increasing discharge energies, cf. Fig. 4. It is assumed that with increasing discharge energy, less melted material is completely removed and thus increases relative rim

๑ BercoCut Pro $\square$ CobraCut A $\square$ Topas Plus H

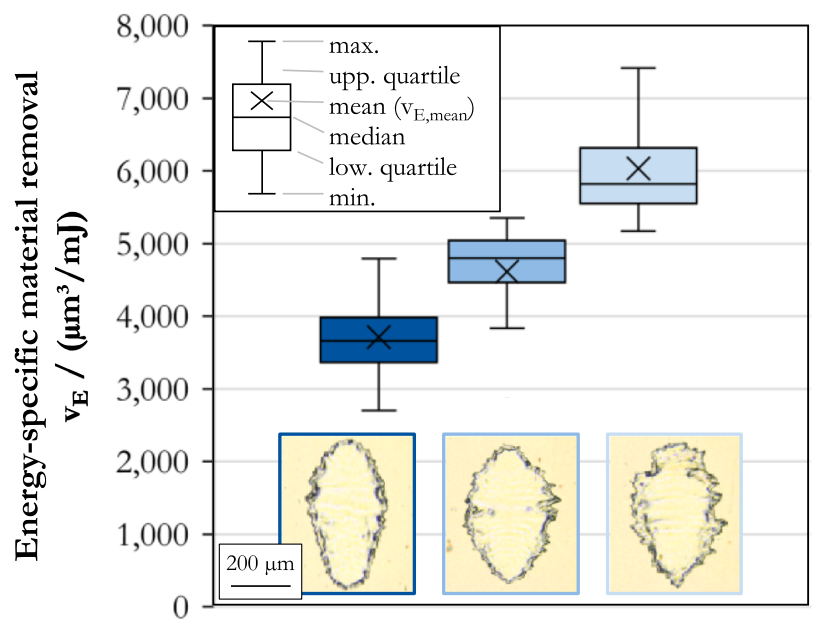

Fig. 5 Influence of the electrode material on energy-specific material removal for discharge energies of $15 \leq \mathrm{We} \leq 50 \mathrm{~mJ}$ volume. The removal efficiency $\eta$ for a single discharge, which can be calculated with the remelted material volume, cf. [5], is thus expected to decrease with increasing discharge energy.

On the other hand, lower relative rim volumes are consistently achieved using the $\gamma$-brass wire than with the brass wire. The molten material is removed more effectively and solidifies to a lesser extent at the crater rim. Also in absolute terms, the craters generated with the $\gamma$-brass wire have an average rim height that is around $45 \%$ lower than that of the brass wire. In addition to lower rim volumes, larger crater

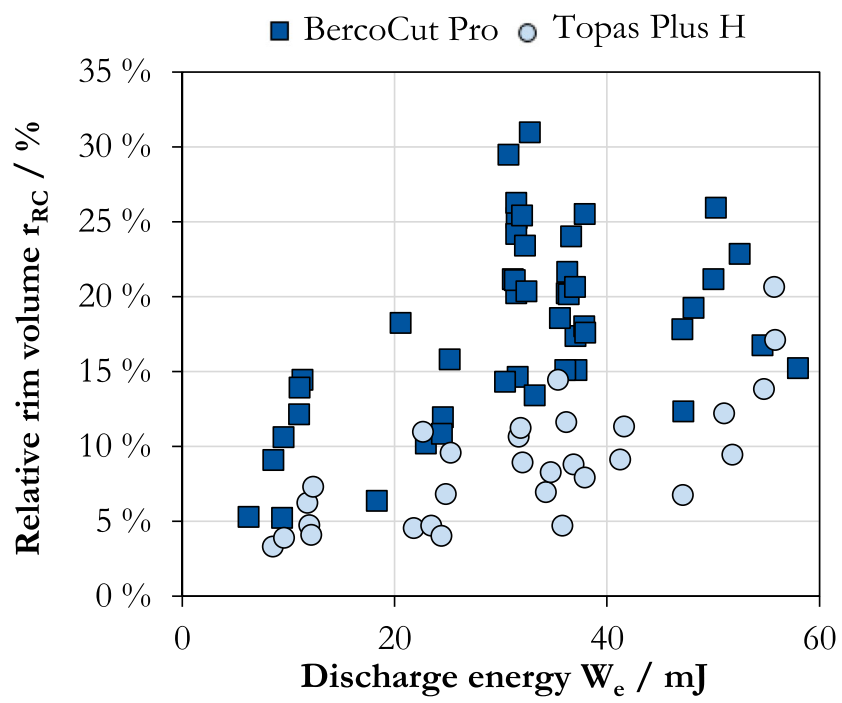

Fig. 6 Influence of the electrode material on relative rim volume over discharge energy 
volumes are found. For equal discharge energies, craters are around $20 \%$ deeper when using the $\gamma$-brass wire. The crater width orthogonal to the wire direction (crater dimension a) is also significantly increased for both $\gamma$-brass and zinc-coated wire compared to the brass wire, while crater dimension $b$ is not significantly influenced by the wire type. For the zinccoated wire CobraCut A, particularly low rim height and large crater dimension a are identified, cf. Fig. 5. However, the crater depth achieved is on average smaller than for craters generated using the $\gamma$-brass wire electrode.

\subsection{Continuous EDM process}

The transferability of the single discharge test results to the continuous erosion process is examined making useful simplifications at several points. Comparing the wire electrodes and taking into account different discharge frequencies, the removal volumes of the single discharge craters are used to determine a theoretical maximum removal rate. This is then compared with the effective removal rate achieved in the tests. As a new assessment characteristic, the removal efficiency $\eta_{R}$ for the continuous erosion process is introduced. It is defined as the quotient of the experimentally determined removal rate $\mathrm{V}_{\mathrm{W} \text {,eff }}$ and the theoretically possible removal rate $\mathrm{V}_{\mathrm{W} \text {,theo. The }}$ calculation is given in the Formulas 3-5.

$\eta_{R}=\frac{V_{W, \text { eff }}}{V_{W, \text { theo }}}$

$V_{W, e f f}=v_{f} \cdot s_{m} \cdot h$

$V_{W, \text { theo }}=V_{W e} \cdot f_{e} \cdot r_{N}$

To obtain the theoretically possible material removal rate $\mathrm{V}_{\mathrm{W} \text {,theo, }}$, the product of the average individual removal volume per discharge $V_{W e}$, the determined effective discharge frequency $\mathrm{f}_{\mathrm{e}}$, and the proportion of normal discharges $\mathrm{r}_{\mathrm{N}}$ (as opposed to short circuit discharges) in the continuous erosion process are calculated. Results of subsidiary tests showed that the underlying assumption that no material removal is achieved with a short circuit discharge is permissible. Furthermore, it is assumed that each normal discharge also causes a discharge crater corresponding to the single discharge tests. The average discharge energy of the standard discharges in the continuous process is determined, and using a regression analysis on the data points of the single discharge tests, the corresponding average material removal is obtained for each wire electrode. Under the given assumptions, the removal efficiency represents an assessment characteristic that gives an approximate measure of the difference between ideal removal processes in single discharge tests and real process conditions.

For the lowest discharge frequency of $P=40$, the removal efficiency is around $\eta_{\mathrm{R}} \approx 34-42 \%$ depending on the electrode material. Higher discharge frequencies result in even smaller removal efficiencies $\eta_{R}$, cf. Fig. 7. A possible reason for the significant differences between theoretical and effective removal rates may be an increased occurrence of abnormal discharge pulses during the continuous erosion due to contamination. The electrical signal does not differ from standard discharges, but the removed single volume might be significantly reduced. Another possibility is the case of multiple melting of the same material volume occurring in the continuous erosion process. The latter strongly depends on the removal efficiency of a single discharge $\eta$, cf [5].

Comparing the removal efficiency $\eta$ of the different wire electrodes, the brass wire has the highest removal efficiency $\eta$ while the $\gamma$-brass wire exhibits the lowest. This is exactly contrary to the result of the wire-specific material removal per discharge. However, the effect of lower efficiency of the two coated wires does not compensate for their larger material removal, so that the absolute removal rate is higher when using these wires.

\section{Conclusions and outlook}

In this paper, an experimental setup for the generation of single discharges on an industrial wire EDM machine has been presented and single discharge craters have been investigated by varying the discharge energy with three different, uncoated and coated wire electrodes. All investigated craters above a discharge energy of $\mathrm{W}_{\mathrm{e}}=5 \mathrm{~mJ}$ have an elliptical shape with the longer semi-axis running along the wire unwinding direction.

An approximately proportional yet slightly degressive correlation was found for the relationship between discharge energy and single removal volume. Using a brass wire, crater volumes of up to $215,000 \mu^{3}$ were measured. Coated wires

$\square$ BercoCut Pro $\square$ CobraCut A $\square$ Topas Plus H

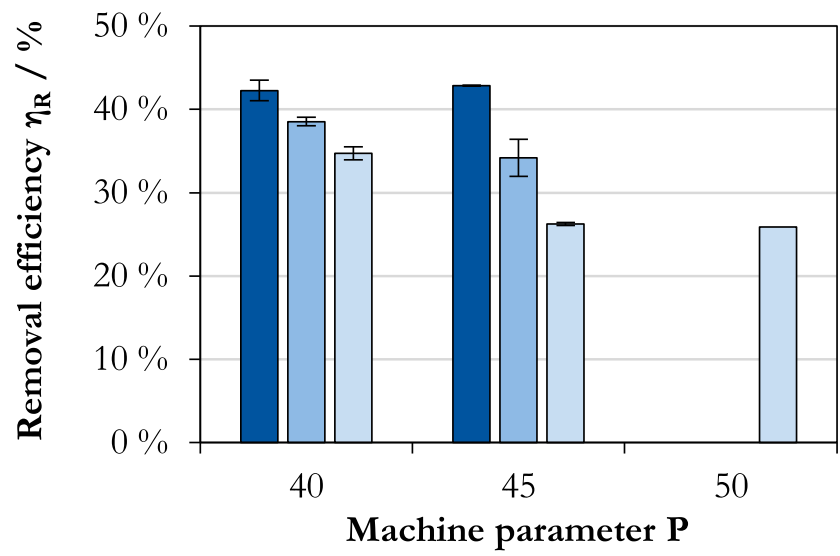

Fig. 7 Influence of the electrode material on removal efficiency over machine parameter $\mathrm{P}$ 
achieve up to $60 \%$ larger removal volumes for the same discharge energy, which is due to the comparatively lower relative rim volume.

The removal efficiency $\eta_{R}$, as the quotient of the real removal rate and the removal rate calculated theoretically on the basis of the individual removal volumes, defines a characteristic for evaluating the discrepancy between ideal removal processes on the basis of individual discharge tests and the real process conditions. In the tests conducted for the continuous process, the brass wire achieved the highest removal efficiency. This amounted to a maximum of around $40 \%$ and thus indicates the need for further research to understand the causes of empirically occurring variance in the removal volumes of normal discharges.

To this end, it is necessary to determine the volume of molten material during a single discharge in order to gain further insight into the influence of the electrode material on the efficiency of the single discharge removal.

\section{Code availability Not applicable}

Funding Open Access funding enabled and organized by Projekt DEAL. This work is partially funded through the subproject T01/"WEDM-functionality" (project number 223500200) associated with the Transregional CRC 136 "Process Signatures" funded by the German National Science Foundation (DFG).

Data availability Not applicable

\section{Declarations}

Conflict of interest The authors declare no competing interests.

Open Access This article is licensed under a Creative Commons Attribution 4.0 International License, which permits use, sharing, adaptation, distribution and reproduction in any medium or format, as long as you give appropriate credit to the original author(s) and the source, provide a link to the Creative Commons licence, and indicate if changes were made. The images or other third party material in this article are included in the article's Creative Commons licence, unless indicated otherwise in a credit line to the material. If material is not included in the article's Creative Commons licence and your intended use is not permitted by statutory regulation or exceeds the permitted use, you will need to obtain permission directly from the copyright holder. To view a copy of this licence, visit http://creativecommons.org/licenses/by/4.0/.

\section{References}

1. Descoeudres A. Characterization of electrical discharge machining plasmas. Dissertation. Lausanne. 137 pp. 2006.

2. Nöthe T. Funkenerosive Mikrobearbeitung von Stahl und Hartmetall durch Schneiden mit dünnen Drähten. Dissertation. Aachen. 86 pp. 2001.

3. Han F, Jiang J, Yu D (2007) Influence of discharge current on machined surfaces by thermo-analysis in finish cut of WEDM. Int J Mach Tools Manuf 47:1187-1196

4. Kamenzky S. Einsatz von pulveradditiviertem Dielektrikum in der Drahterosion. Dissertation. Aachen. 129 pp. 2012.

5. Zhang Y, Liu Y, Shen Y, Ji R, Li Z, Zheng C (2014) Investigation on the influence of the dielectrics on the material removal characteristics of EDM. J Mater Process Technol 214:1052-1061

6. Schwade M. Automatisierte Analyse hochfrequenter Prozesssignale bei der funkenerosiven Bearbeitung von Magnesium für die Medizintechnik. Dissertation. Aachen. 154 pp. 2017.

7. Klocke F, Mohammadnejad M, Holsten M, Ehle L, Zeis M, Klink A (2018) A comparative study of polarity-related effects in single discharge EDM of titanium and iron alloys. Proc CIRP 68:52-57

8. Li Q, Yang X (2020) Study on arc plasma movement and its effect on crater morphology during single-pulse discharge in EDM. Int J Adv Manuf Technol 106:5033-5047

9. Maher I, Sarhan A, Hamdi M (2015) Review of improvements in wire electrode properties for longer working time and utilization in wire EDM machining. Int J Adv Manuf Technol 76:329-351

10. Kruth J-P, Lauwers B, Schacht B, van Humbeeck J (2004) Composite wires with high tensile core for wire EDM. CIRP Ann 53:171-174

11. Prohaszka J, Mamalis A, Vaxevanidis N (1997) The effect of electrode material on machinability in wire electro-discharge machining. J Mater Process Technol 69:233-237

Publisher's note Springer Nature remains neutral with regard to jurisdictional claims in published maps and institutional affiliations. 